\title{
The Interplay Between Employee and Firm Customer Orientation: Substitution Effect and the Contingency Role of Performance-Related Rewards
}

\author{
Dennis Herhausen, ${ }^{1}$ Luigi M. De Luca ${ }^{2}$ and Michael Weibel ${ }^{1}$ \\ ${ }^{1}$ Institute of Marketing, University of St. Gallen, Dufourstr. 40a, 9000 St. Gallen, Switzerland, and ${ }^{2}$ Cardiff \\ Business School, Cardiff University, Colum Drive, Cardiff CF10 3EU, UK \\ Corresponding author email: dennis.herhausen@unisg.ch
}

\begin{abstract}
This paper identifies and explains a potential tension between a firm's emphasis on customer orientation $(\mathrm{CO})$ and the extent to which employees value $\mathrm{CO}$ as a success factor for individual performance. Based on self-determination theory and $\mathrm{CO}$ implementation research, the authors propose that firm $\mathrm{CO}$ may represent both autonomous and controlled motivations for $\mathrm{CO}$, but that employees' $\mathrm{CO}$ is more strongly linked to individual performance when employees experience solely autonomous motivation. Hence, the authors expect a substitution effect whereby the link between employees' $\mathrm{CO}$ and their performance is weaker when firm $\mathrm{CO}$ is high. Furthermore, the authors examine a boundary condition for the previous hypothesis and propose that performance-contingent rewards have a positive effect on the internalization of the extrinsic motivation stemming from firm CO. Two multilevel studies with 979 employees and 201 top management team members from 132 firms support these hypotheses. Against previous research, these findings offer a new perspective on the effectiveness of $\mathrm{CO}$ initiatives, propose employees' motivational states as the theoretical explanation for the heterogeneity in the link between employee $\mathrm{CO}$ and performance, and reappraise the role of performance-contingent rewards in $\mathrm{CO}$ research. Managerial implications for the effective implementation of customer-oriented initiatives within firms are provided.
\end{abstract}

\section{Introduction}

It is widely accepted that a firm's ability to benefit from customer orientation (CO) is contingent on the employees who implement it (e.g. Brach et al., 2015; Kennedy, Lassk and Goolsby, 2002; Lin et al., 2016). Many companies are acting on this belief, as witnessed by organization-wide $\mathrm{CO}$ initiatives such as GE's Gold Standard in Marketing Program and Macy's Customer Centric Initiative. However, many of these efforts

The authors thank Heiner Evanschitzky and the anonymous reviewers, Ajay Kohli, and participants of a research seminar at the University of St. Gallen for their helpful comments on previous drafts of this paper. are ineffective. For example, evidence indicates that, while $56 \%$ of firms perceive themselves as being very customer oriented, only $12 \%$ of their customers agree (CMO Council, 2008). Critical to the success of CO initiatives is the understanding of what motivates employees to adopt a $\mathrm{CO}$.

The $\mathrm{CO}$ implementation literature suggests two such motivations: the need to comply with the normative mandate of the firm (Gebhardt, Carpenter and Sherry, 2006) and the self-driven recognition of $\mathrm{CO}$ as an important job value (Zablah et al., 2012). These two motivations can be differentiated in line with self-determination theory (SDT), a macro theory of motivation that explains how employees identify with values and behaviours 
that are endorsed by their firm (Gagné and Deci, 2005; Ryan and Deci, 2000). First, organizational leaders establish, diffuse and institutionalize customer-oriented values and norms in top-down CO initiatives (e.g. Stock and Hoyer, 2005). In line with the normative perspective of the $\mathrm{CO}$ literature, SDT suggests that, as a result of organizational CO initiatives, employees will become more customer oriented in response to an inducement by an external agent. This external source of $\mathrm{CO}$ may lead employees to internalize the importance of $\mathrm{CO}$ in their work value set (i.e. autonomous motivation) and/or to act based on a certain sense of pressure and obligation (i.e. controlled motivation). Second, employees' identification with $\mathrm{CO}$ as a work-related value may also be a self-induced choice, driven by inherent personal interest (i.e. autonomous motivation). Thus, employee $\mathrm{CO}$ can result from a purely autonomous motivation (low external stimulus for $\mathrm{CO}$, high personal interest in $\mathrm{CO}$ ), from a relatively controlled motivation (high external stimulus for $\mathrm{CO}$, low personal interest in $\mathrm{CO}$ ) or from a combination of both (high external stimulus for $\mathrm{CO}$, high personal interest in $\mathrm{CO}$ ).

Importantly, there is growing consensus in recent SDT research that autonomous and controlled motivations coexist independently of each other in the work context (e.g. Cerasoli, Nicklin and Ford, 2014; Gerhart and Fang, 2015; Grant et al., 2011). Moreover, SDT research indicates that the combination of controlled and autonomous motivations towards the same behaviour may lead to different performance outcomes for employees (Gagné and Deci, 2005). For example, Grant et al. (2011) found across two studies that the same level of initiative among highly autonomously motivated employees was more positively related to performance when they reported low levels of controlled motivation. This may pinpoint a potential tension between firm $\mathrm{CO}$ and individual $\mathrm{CO}$. If employees perceive firm $\mathrm{CO}$ as controlled motivation, $\mathrm{CO}$ will not be fully internalized and therefore the relationship between employee $\mathrm{CO}$ and performance will be weaker. In contrast, if firm $\mathrm{CO}$ is perceived as a driver of autonomous motivation, the employee $\mathrm{CO}$-performance link will be stronger, owing to a higher degree of $\mathrm{CO}$ internalization. Despite the relevance of this issue for understanding employees' motivation for $\mathrm{CO}$, no previous study has investigated the cross-level interaction between organizational $\mathrm{CO}$ and employee $\mathrm{CO}$ in relation to employee performance. Thus, the overarching research question of this study is: Under what circumstances will firm $\mathrm{CO}$ induce autonomous (versus controlled) motivation?

While taking into account a wide range of individual and organizational factors, we identify performance-related rewards as the key contingency variable to address our research question (Gerhart and Fang, 2015). We advance that performance-contingent rewards may help direct firm CO towards increasing employees' autonomous motivation for $\mathrm{CO}$, and have a positive effect on the internalization of firm $\mathrm{CO}$ (Gagné and Deci, 2005; Ryan, Mims and Koestner, 1983). To date, there is limited knowledge of the role of performance-related rewards in $\mathrm{CO}$ research; existing studies advancing a direct link between performance-related rewards, employee $\mathrm{CO}$ and employee performance often report non-significant results (e.g. Liao and Chuang 2004; MacKenzie, Podsakoff and Rich, 2001; Schmitz and Ganesan 2014). Recent contributions have suggested adopting a contingency approach when studying the effectiveness of performance incentives (Gagné and Deci 2005; Gerhart and Fang, 2015). Following this line of research, in this study we examine how the interplay between performance-contingent rewards, firm $\mathrm{CO}$ and employee $\mathrm{CO}$ affects employee performance.

We test our conceptual framework through two multilevel studies consisting of three independent samples composed of 979 employees and 201 top management team members from 132 firms. We use two different contexts, back-office employees in Study 1 and customer-contact employees from various business-to-business (B2B) companies in Study 2, to strengthen the external validity of our findings. In Study 1, we find that employee CO is positively related to employee performance when firm CO is low, but not when firm CO is high. In Study 2 we replicate this result and additionally find that performance-contingent rewards counteract the buffering effect of firm $\mathrm{CO}$, such that when these rewards are present, the positive relationship between employee $\mathrm{CO}$ and performance holds under both high and low levels of firm CO.

Our work provides three major contributions to the management literature (see Table 1). First, we identify an interesting substitution effect between the emphasis a firm places on $\mathrm{CO}$ and the extent to which employees perceive it as an individual success factor. Our model suggests that 
Table 1. Overview of existing literature and contributions of this study

\begin{tabular}{|c|c|c|c|c|}
\hline & Key studies & Key findings & Research gap & Contributions of this study \\
\hline $\begin{array}{l}\text { Influence of } \\
\text { firm's CO on } \\
\text { employees' CO }\end{array}$ & $\begin{array}{l}\text { Boles et al., } 2001 \\
\text { Cross et al., } 2007 \\
\text { Guenzi, De Luca and } \\
\text { Troilo, } 2011 \\
\text { Liao and Subramony, } \\
2008 \\
\text { Williams and Attaway, } \\
1996\end{array}$ & $\begin{array}{l}\text { Firm } \mathrm{CO} \text {, both in terms of } \\
\text { top management teams' } \\
\mathrm{CO} \text { and organizational } \mathrm{CO} \text {, } \\
\text { increases employees' } \mathrm{CO} \text {. }\end{array}$ & $\begin{array}{l}\text { Previous research did } \\
\text { not differentiate } \\
\text { between controlled } \\
\text { and autonomous } \\
\text { motivation of } \\
\text { employees for CO, } \\
\text { nor did it consider the } \\
\text { implications of these } \\
\text { different kinds of } \\
\text { motivation. }\end{array}$ & $\begin{array}{l}\text { Contribution 1: Identifying } \\
\text { and explaining a tension } \\
\text { between the firm's } \\
\text { emphasis on CO and } \\
\text { employees' } \\
\text { internalization of CO and } \\
\text { investigating its } \\
\text { implications. }\end{array}$ \\
\hline $\begin{array}{l}\text { Influence of } \\
\text { employees' CO } \\
\text { on employees' } \\
\text { performance }\end{array}$ & $\begin{array}{l}\text { Boles et al., } 2001 \\
\text { Cross et al., } 2007 \\
\text { Donavan, Brown and } \\
\text { Mowen, } 2004 \\
\text { Franke and Park, } 2006 \\
\text { Kennedy, Lassk and } \\
\text { Goolsby, } 2002 \\
\text { Zablah et al., } 2012\end{array}$ & $\begin{array}{l}\text { Employees' CO increases } \\
\text { several desirable job } \\
\text { outcomes, including } \\
\text { employees' performance, } \\
\text { both for back-office and } \\
\text { customer-contact } \\
\text { employees in service and } \\
\text { sales contexts. }\end{array}$ & $\begin{array}{l}\text { Meta-analytic } \\
\text { investigations found } \\
\text { unexplained } \\
\text { heterogeneity in the } \\
\text { relationship between } \\
\text { employees' CO and } \\
\text { their performance. }\end{array}$ & $\begin{array}{l}\text { Contribution 2: } \\
\text { Investigating the } \\
\text { moderating role of the } \\
\text { firm's CO in the } \\
\text { relationship between } \\
\text { employees' CO and their } \\
\text { performance. }\end{array}$ \\
\hline $\begin{array}{l}\text { Influence of } \\
\text { performance- } \\
\text { contingent } \\
\text { rewards on } \\
\text { employees' CO } \\
\text { and employees' } \\
\text { performance }\end{array}$ & $\begin{array}{l}\text { Liao and Chuang, } 2004 \\
\text { MacKenzie, Podsakoff } \\
\text { and Rich, } 2001 \\
\text { Schmitz and Ganesan, } \\
2014\end{array}$ & $\begin{array}{l}\text { Previous research found no } \\
\text { significant associations } \\
\text { between performance- } \\
\text { contingent rewards and (a) } \\
\text { store-level CO, (b) } \\
\text { employees' customer- } \\
\text { directed efforts and (c) } \\
\text { employee performance. }\end{array}$ & $\begin{array}{l}\text { Previous research did } \\
\text { not consider the } \\
\text { interplay between } \\
\text { performance- } \\
\text { contingent rewards } \\
\text { and the controlled } \\
\text { motivation of firm } \\
\text { CO. }\end{array}$ & $\begin{array}{l}\text { Contribution 3: Resolving } \\
\text { the tension between the } \\
\text { firm's emphasis on CO } \\
\text { and employees' } \\
\text { internalization of CO by } \\
\text { investigating the } \\
\text { moderating role of } \\
\text { performance-contingent } \\
\text { rewards in the } \\
\text { relationship between the } \\
\text { firm's CO, employees' CO } \\
\text { and employees' } \\
\text { performance. }\end{array}$ \\
\hline
\end{tabular}

the failure to consider these two factors simultaneously may jeopardize the implementation of customer-oriented initiatives. Second, we empirically support the moderating role of firm $\mathrm{CO}$ as a new source of heterogeneity in the relationship between employees' $\mathrm{CO}$ and their performance, and theoretically explain this effect by considering the different motivational states of employees.

Third, our study brings new knowledge concerning the role of performance-contingent rewards in customer-oriented firms; our contingency approach complements and extends previous studies focusing on the direct effect of rewards. Our study further informs the design of performance-contingent rewards by reporting the effectiveness of a specific type of incentive (i.e. directly performance-salient incentives). Also, our results offer managers a unified framework for understanding and managing the complexity of autonomous and controlled motivations within $\mathrm{CO}$ initiatives.

\section{Conceptual background and hypotheses}

\section{Baseline relationships from prior research}

Employee $\mathrm{CO}$, defined as an attitude and a set of behaviours to meet customer needs on the job (e.g. Brach et al., 2015; Zablah et al., 2012), is an important antecedent of individual performance. For example, customer-contact employees with a high $\mathrm{CO}$ are more likely to identify a customer's needs and the services or products that will best solve customer problems, thus enhancing their performance (Boles et al., 2001; Cross et al., 2007). However, even those who have no direct customer contact should focus their efforts on external customers in order to fulfil their job expectations (Kennedy, Lassk and Goolsby, 2002; Lin et al., 2016). CO affects the performance of back-office employees by motivating collaborative exchanges with customercontact employees (Liao and Subramony, 2008), and enhances job satisfaction, commitment 
and organizational citizenship behaviours (Donavan, Brown and Mowen, 2004), which will further improve employee performance.

Scholars further suggest that firm $\mathrm{CO}$, defined as organization-wide culture, practices and processes that help to put the customer's interests first (Deshpandé, Farley and Webster, 1993), is transferred to employees through the dissemination of shared values and behavioural norms (Stock and Hoyer, 2005). In line with these suggestions, previous research indicates that firm $\mathrm{CO}$ is positively related to the $\mathrm{CO}$ of both customer-contact and back-office employees. Liao and Subramony (2008) used the CO of the top management team as a proxy for firm $\mathrm{CO}$ and found that individual employees in both customercontact and back office roles are motivated to be more customer oriented by the top management team. Other studies have revealed that a customeroriented organizational culture and processes positively affect employee CO (e.g. Guenzi, De Luca and Troilo, 2011; Williams and Attaway, 1996).

The studies of Boles et al. (2001) and Cross et al. (2007) combined the two effects, indicating that firm CO influences employee performance via employee $\mathrm{CO}$, while not formally testing for an indirect effect. In sum, a review of key studies provides ample support for the notion that employee $\mathrm{CO}$ is positively related to employee performance, firm $\mathrm{CO}$ is positively related to employee $\mathrm{CO}$, and firm $\mathrm{CO}$ may have a positive indirect effect on employee performance via employee $\mathrm{CO}$. We position our study in this literature by using these relationships as baseline effects in our analyses (see Figure 1).

\section{Substitution between firm and employee $\mathrm{CO}$}

In the preceding subsection, we reviewed the $\mathrm{CO}$ implementation research, which indicates that firm $\mathrm{CO}$ is an important antecedent of employee $\mathrm{CO}$. While generally supporting the effectiveness of external motivation on individual behaviour, SDT makes a key distinction between autonomous and controlled motivation, both stemming from external sources (Gagné and Deci, 2005). Autonomous motivation means acting on one's own volition and experiencing a sense of choice in adopting a certain behaviour (Ryan and Deci, 2000). We consider firm $\mathrm{CO}$ as a possible driver of autonomous motivation for $\mathrm{CO}$ because previous research found that at least some employees unreservedly adopted a $\mathrm{CO}$ advocated by the firm (Harris and Ogbonna, 2000). Controlled motivation means acting under external pressure and experiencing no choice in adopting a certain behaviour (Ryan and Deci, 2000). Given that CO initiatives often instil a sense of pressure, which urges employees to adopt $\mathrm{CO}$, we consider firm $\mathrm{CO}$ to be also a possible driver of controlled motivation for $\mathrm{CO}$.

For instance, the terminology used to describe customer-oriented initiatives often reflects the controlled motivation concept: customer-oriented values and norms are 'inculcated' (Lichtenthal and Wilson 1992, p. 194), and employees are 'indoctrinated' (Gebhardt, Carpenter and Sherry, 2006, p. 48). Indeed, the need for employees to keep their jobs, meet managers' expectations and embrace the organizational culture may push them to comply with $\mathrm{CO}$, irrespective of their autonomous motivation towards the behaviour. Thus, the extrinsic motivation of firm $\mathrm{CO}$ varies in its degree of self-determination and may be both a driver of autonomous and controlled motivation for CO (Gagné and Deci, 2005). In contrast, the intrinsic motivation of employees' personal interest in $\mathrm{CO}$ is invariantly self-determined and thus solely a driver of autonomous motivation for CO (Gagné and Deci, 2005).

Following Amabile (1993), Cerasoli, Nicklin and Ford (2014), Gerhart and Fang (2015) and Grant et al. (2011), among others, we conceptualize autonomous and controlled motivations as orthogonal in the work context (see Figure 2). In support for this conceptualization, empirical studies have found - based on non-significant correlations - that autonomous and controlled motivations are independent of each other, and concluded that these two motivations 'are essentially orthogonal' (Amabile et al., 1994, p. 958). In line with recent meta-analytic investigations (Cerasoli, Nicklin and Ford, 2014), we propose that both autonomous and controlled motivations may lead to a desired behaviour (e.g. employee $\mathrm{CO})$. The effectiveness of such behaviour, when it occurs, is another matter as the different kinds of motivation that lead to the desired behaviour may also determine its ability to produce desired outcomes (Grant et al., 2011). Thus, it is important to understand how employees' motivation for $\mathrm{CO}$ influences the effectiveness of their $\mathrm{CO}$. We expect employee $\mathrm{CO}$ to be more strongly related to performance under purely autonomous 


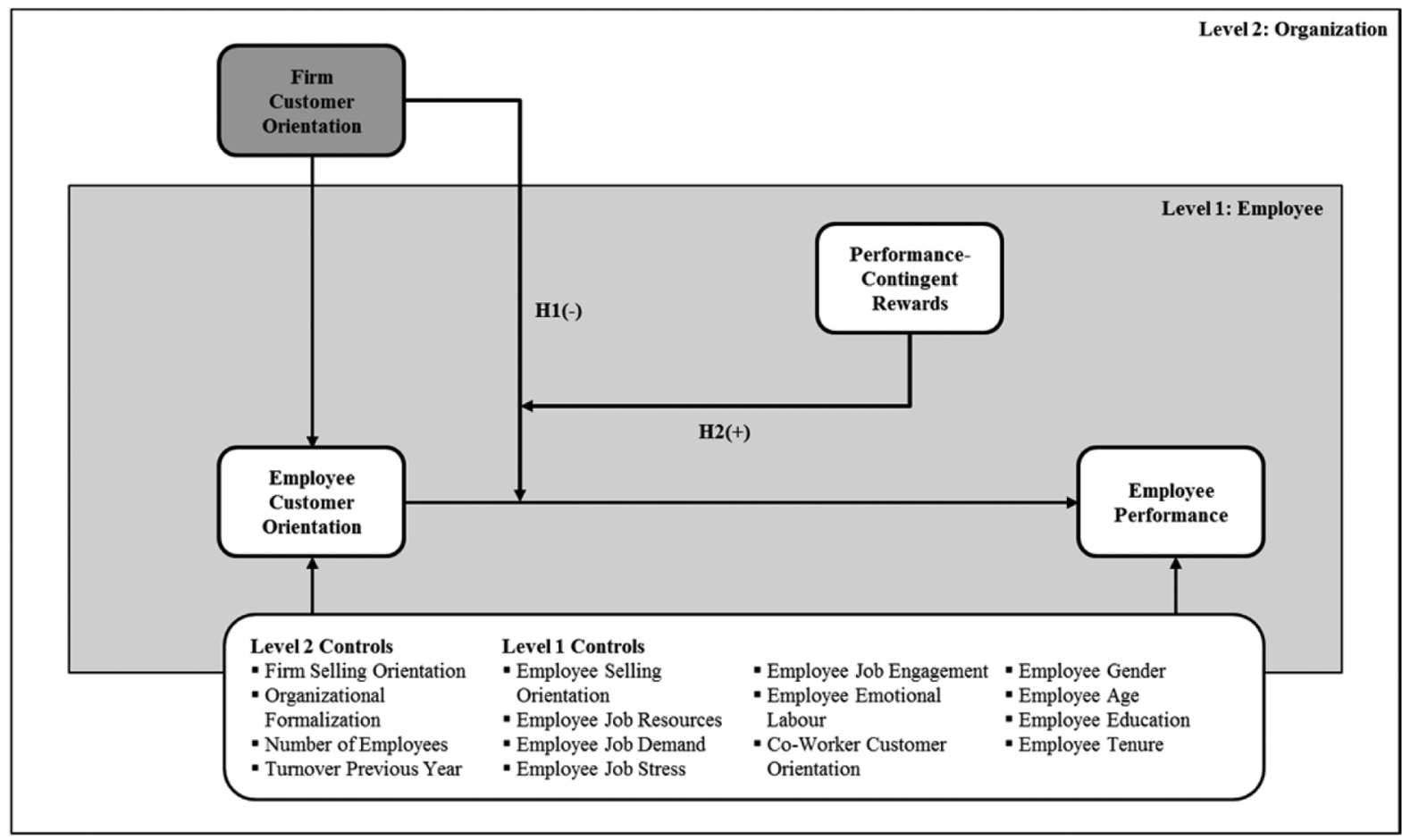

Employee Data $\square$ Top Management Team Members / Aggregated Employees Data

Baseline relationships and controls from prior research

New relationships tested in this study

Figure 1. Conceptual framework: the interplay between firm and employee customer orientation

motivation. In this situation, we expect the benefits of $\mathrm{CO}$ for individual performance to exceed those generated when employees experience relatively controlled motivation or high levels of both autonomous and controlled motivation.

The strongest link between employee $\mathrm{CO}$ and employee performance should occur when motivation is purely autonomous, as employees have an inherent personal interest in $\mathrm{CO}$ in spite of the low level of firm CO. Under these circumstances, employees are more likely to engage in the most effective forms of $\mathrm{CO}$, as their autonomous motivation helps them maintain attention, interest, energy and enthusiasm, thus facilitating effective effort (Gagné and Deci, 2005). Indeed, Ryan and Deci (2000, p. 69) argue that the more autonomous the motivation, the higher its quality and the more authentic it is, which means that employees 'have more interest, excitement, and confidence, which in turn is manifest ... as enhanced performance'. In addition, low levels of firm $\mathrm{CO}$ should make individual $\mathrm{CO}$ behaviours stand out more, granting additional performance advantages to the employees promoting and adopting such behaviours, relative to others.

At the opposite extreme, when employee's inherent personal interest in $\mathrm{CO}$ is low despite the high firm $\mathrm{CO}$, we expect a weaker link between employee $\mathrm{CO}$ and employee performance. This is because low levels of personal interest in $\mathrm{CO}$, despite the high emphasis on $\mathrm{CO}$ by the firm, is likely to lead employees towards mere compliance, which may often result in an uninspired approach to addressing customer needs, and low levels of effort towards customer-related obligations (Gagné and Deci, 2005). Therefore, the combination of low personal interest in $\mathrm{CO}$ and high firm $\mathrm{CO}$ is likely to result in firm $\mathrm{CO}$ being perceived as controlled motivation, which is met by a certain degree of resistance by the employee (Harris and Ogbonna 2000).

Even when both firm CO and employees' personal interest in $\mathrm{CO}$ are high, we expect that CO may still be less strongly related to performance than under pure inherently autonomous motivation. We propose that when both individual 


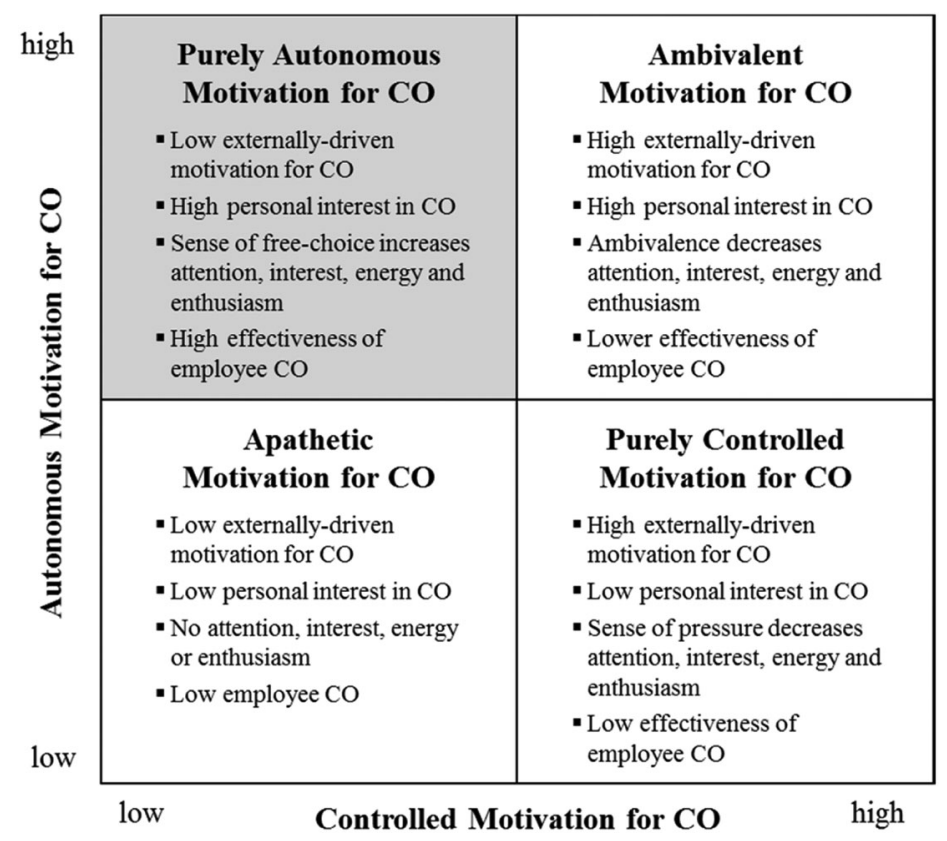

Figure 2. Autonomous and controlled motivations for employee $C O$

Notes: Based on Grant et al. (2011). Although earlier work in SDT treats autonomous and controlled motivations as opposite poles of a single continuum, there is growing consensus with regard to conceptualizing these motivations as orthogonal in the work context (e.g. Amabile, 1993; Cerasoli, Nicklin and Ford, 2014; Gerhart and Fang, 2015). Empirically, Amabile et al. (1994, p. 958) and Grant et al. (2011, p. 245) found in several samples that autonomous and controlled motivations are independent. We expect the effectiveness of employee CO (i.e. its performance effect) to be highest under conditions of purely autonomous motivation (grey area)

and firm $\mathrm{CO}$ motivations are high, employees may experience motivational ambivalence and conflicting goals (Fong and Tiedens, 2002; Grant et al., 2011). Autonomous motivation will pull employees in the direction of $\mathrm{CO}$, as they view it as bringing inherent enjoyment and fulfilment to their work (Grant, 2008). In contrast, controlled motivation provides employees with a perception of being externally directed (Gagné and Deci, 2005), which may reduce the willingness to allocate resources and efforts to engage in effective forms of $\mathrm{CO}$. In addition, higher levels of controlled motivation will create an internal environment whereby $\mathrm{CO}$ is socially expected; in this context, customer-oriented individuals are less likely to emerge or to attribute unique performance advantages to their $\mathrm{CO}$. Thus, the presence of both autonomous and controlled motivations is likely to create a motivational ambivalence that can at least partially reduce the benefits of high autonomous motivation alone (Grant et al., 2011).

Complementary explanations for why the effectiveness of $\mathrm{CO}$ may be highest under pure autonomous motivation are offered by emotional labour theory and the $\mathrm{CO}$ literature. Emotional labour theory differentiates between surface acting and deep acting as two outcomes of employees' CO (Yoo and Arnold 2016) and suggests that the link between employee $\mathrm{CO}$ and performance is stronger when the emotion regulation of employees is more authentic (i.e. deep acting: Allen et al., 2010; Brach et al., 2015). As autonomous motivation is associated with higher internalization of behaviours and thus with authenticity, we expect employees' $\mathrm{CO}$ to be more strongly associated with their performance if they are fully autonomously motivated for $\mathrm{CO}$. The $\mathrm{CO}$ literature echoes this idea by highlighting the positive performance effects of customer-oriented authenticity (Hennig-Thurau et al., 2006).

In summary, based on SDT, we expect employee $\mathrm{CO}$ to be linked to autonomous motivation, and firm $\mathrm{CO}$ to be linked to both autonomous and controlled motivation. Building on this, we predict that employee $\mathrm{CO}$ will be most strongly associated with performance when employees experience high autonomous and low controlled motivation 
due to the experience of choice, energy and enthusiasm. This condition is more likely characterized by high personal interest for $\mathrm{CO}$ and low firm $\mathrm{CO}$. However, the performance payoff of employee $\mathrm{CO}$ will diminish when motivation is both autonomous and controlled (i.e. high personal interest for $\mathrm{CO}$, high firm $\mathrm{CO}$ ), owing to ambivalence and associated self-regulatory efforts and stress. The payoff from employee $\mathrm{CO}$ is also likely to suffer when motivation is relatively controlled (i.e. low personal interest for $\mathrm{CO}$, high firm $\mathrm{CO}$ ), owing to the predominant effect of perceived external pressure. Thus:

H1: Other things being equal, the firm's $\mathrm{CO}$ negatively moderates the positive relationship between employees' $\mathrm{CO}$ and their performance, such that the higher the firm's $\mathrm{CO}$, the weaker the relationship.

\section{Performance-contingent rewards as a boundary condition}

Performance-contingent rewards are defined as the performance-related compensation received by employees (e.g. Procter et al., 1993). Previous research has found no significant associations between performance-contingent rewards and storelevel CO (Liao and Chuang, 2004), employees' customer-directed efforts (Schmitz and Ganesan, 2014) and employee performance (MacKenzie, Podsakoff and Rich, 2001). Thus, we treat these rewards as exogenous to a firm's $\mathrm{CO}$, as they can be adopted by firms with either high or low CO. ${ }^{1}$

An important aspect of SDT is that 'extrinsic motivation can vary in the degree to which it is autonomous versus controlled' (Gagné and Deci 2005 , p. 334), and that performance-contingent rewards 'may actually have a net positive effect on autonomous motivation' (Gerhart and Fang, 2015 , p. 505). This corresponds to the central proposition of SDT that 'when a socially-valued activity is prompted by extrinsic motivation in an autonomy-supportive social context, people will tend to internalize and integrate the regulation of that behaviour' (Gagné and Deci, 2005, p. 349). This view challenges the strong assumption in

\footnotetext{
${ }^{1}$ This point is reinforced by the non-significant correlation between organizational $\mathrm{CO}$ and performance-contingent rewards that we found in our data.
}

previous theories on work motivation, such as cognitive evaluation theory, according to which extrinsic rewards are always detrimental for the individual internalization of focal behaviours (Deci, Koestner and Ryan, 1999; Gerhart and Fang, 2015). Thus, in line with SDT, we expect performance-contingent rewards to mitigate the substitution effect between employee $\mathrm{CO}$ and firm CO. We advance three related theoretical explanations to articulate our hypothesis.

First, performance-contingent rewards foster the perception of competence among employees and provide them with more satisfaction of their need for individual autonomy (Hohenberg and Homburg, 2016; Ryan, Mims and Koestner, 1983). This has a positive effect on the internalization of extrinsic motivation, which therefore decreases the chances that firm $\mathrm{CO}$ is perceived as a form of controlled motivation. Second, the marketing literature typically suggests that the superior value generated by a $\mathrm{CO}$ is shared between the firm and its customers (Narver and Slater, 1990). While customers benefit from better and more customized services, firms benefit from superior customer, market and financial performance. In this context, the introduction of performance-contingent rewards represents a mechanism that employees can leverage to appropriate a share of the value that they generate through their customer-oriented behaviour, which otherwise would only benefit the firm and the customer. This again should help in the internalization of the otherwise relatively controlled motivation of firm CO. Third, a recent meta-analysis found that directly performancesalient incentives, such as performance-contingent rewards, 'impart a competence-boosting message, thus also boosting intrinsic motivation' (Cerasoli, Nicklin and Ford, 2014, p. 983). In line with this finding, Gerhart and Fang (2015, p. 498) posit that: "employees generally feel inequitably treated if extrinsic rewards do not correspond to their performance, and inequity will negatively influence motivation and creativity'. This can reinforce the mixed messages associated with ambivalent motivation (Grant et al., 2011) because employees will be more likely to interpret an ambivalent motivation as externally controlled, and will be less creative in addressing and satisfying customer needs, both factors leading to a weaker link between their individual $\mathrm{CO}$ and performance. Following this reasoning, the substitution effect between firm $\mathrm{CO}$ and employee $\mathrm{CO}$ in the link 
with employee performance should be observed in conditions of low performance-contingent rewards, but not in conditions of high-performance rewards:

$H 2$ : Other things being equal, the substitution effect of the firm's $\mathrm{CO}$ on the relationship between employees' $\mathrm{CO}$ and their performance is weaker when employees receive higher levels of performance-contingent rewards.

\section{Study 1}

\section{Data collection and measures}

For Study 1, we gathered data from a convenience sample of the top management teams, back-office employees and managerial key informants in 77 German manufacturing firms from various industries taking part in executive education at the first author's university. All firms received a benchmark report as an incentive. We pretested the measurement scales with seven top management team members and 15 employees during a company workshop. None of the pre-test participants took part in the main study. The exclusion of seven firms because of missing data led to a final sample of matched data from 201 top management team members and 813 back-office employees from 70 firms. We used multiple data sources to avoid same-source bias. Specifically, we used online surveys to collect data on firm $\mathrm{CO}$ from top management team members and data on employee $\mathrm{CO}$, gender, age, education, tenure and performance from employees. We collected data on numbers of employee and turnover from company records. We found no systematic differences in the means for demographics or other study constructs between early and late respondents.

Appendix S1 provides an overview of all measurement items and reliability measures; Table 2 displays means, standard deviations and average variance extracted. All scales had satisfactory Cronbach's alpha values. We used the employee CO scale from Liao and Subramony (2008) because this measure is uniquely suitable for employees with no direct customer contact. In addition, we aggregated the $\mathrm{CO}$ scores of top management team members, measured using the same scale as in Liao and Subramony (2008), to capture the customer-related attitudes of senior managers as a proxy for the firm's CO. In fact, employees without direct customer contact are likely to look to the top management team as a signifier of the firm's CO (Liao and Subramony, 2008). We obtained statistical support for aggregating top management team members' answers at the firm level (ICC [1] = 0.36 ; ICC $[2]=0.65$ ). We assessed employee performance with a self-report scale based on the measure employed by Wieseke et al. (2009). We applied a subjective scale to compare the performance of employees from different firms (Homburg, Müller and Klarmann, 2011) and a self-report measure because many participating firms would not allow managers to share employees' individual performance information. We adjusted the performance measure to capture employees' performance relative to colleagues from the same firm (i.e. employee performance $=$ individual performance-mean individual performance within the firm). ${ }^{2}$

We included a number of potentially important factors as control variables both at the firm level and employee level: organizational formalization, measured with the scale of Jansen, Van Den Bosch and Volberda (2006), because it limits employee autonomy and thus may influence the employee CO-performance relationship; employee job resources, captured by the quality of internal cooperation, because in addition to $\mathrm{CO}$ as a crucial job resource for employees (Zablah et al., 2012), the quality of contact to and collaboration with internal partners is an important job resource, which may affect both employee $\mathrm{CO}$ and performance (Plouffe et al., 2016); employee job demand, measured with an item based on Dwyer and Ganster (1991), because the demandingness of work-related activities may both directly affect employee $\mathrm{CO}$ and performance and influence the employee CO-performance relationship (Zablah et al., 2012); employee job stress, measured as the number of sick days (e.g. Dwyer and Ganster, 1991), because stress may negatively affect both employee $\mathrm{CO}$ and performance (Zablah et al., 2012); employee job engagement, measured with an item based on Rich, Lepine and Crawford (2010), because this positive, work-related affective-motivational state of mind may increase

\footnotetext{
${ }^{2}$ The correlation between the adjusted and the unadjusted measures of performance is very high $(r=0.93, p<$ 0.001 ), and using an unadjusted performance measure led to similar results in the main analysis and the robustness tests.
} 


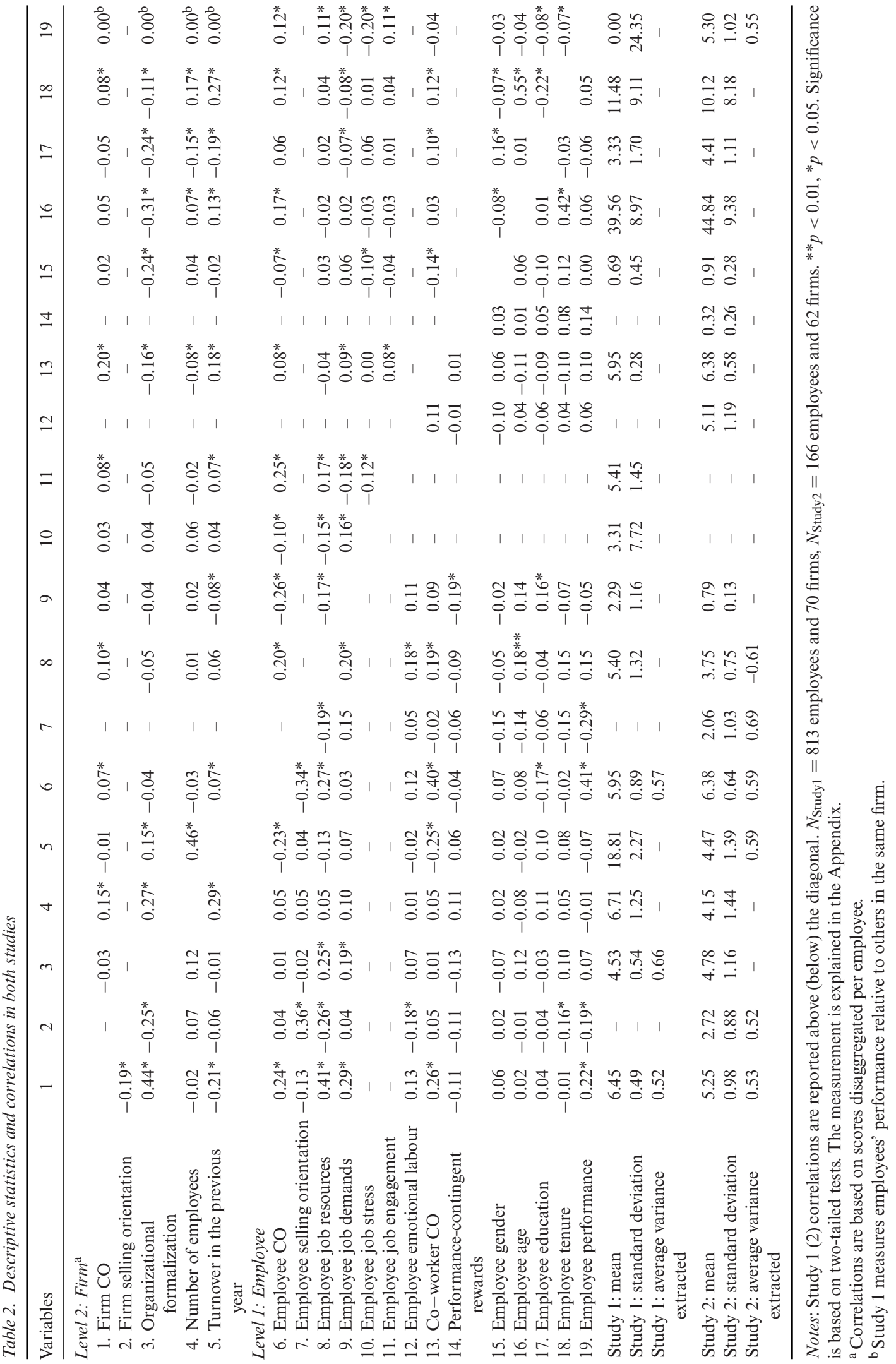


both employee $\mathrm{CO}$ and performance (Zablah et al., 2012); and co-worker $\mathrm{CO}$ because the $\mathrm{CO}$ of other employees may increase employee performance (Menguc et al., 2016). In addition, we control for number of employees, turnover in the previous year, and employee gender, age, education and tenure.

\section{Measurement model and common method bias}

Two confirmatory factor analyses (CFAs) of the top management and employee data indicated a good fit between the measurement model and the data (top management: $\chi^{2}(2)=3.57$; CFI $=$ 0.99; RMSEA $=0.06$; employees: $\chi^{2}(3)=7.65$; CFI $=0.99 ;$ RMSEA $=0.04)$. We combined multiple sources and calculated deviation scores for the dependent variable (i.e. employee performance) to reduce single-source bias and common method bias. We also constructed the items and questionnaire as concisely as possible, minimized potential comprehension problems with pre-tests and included moderating effects in our statistical analyses, thereby reducing the potential for common method bias.

\section{Data analysis strategy}

Because of the multilevel nature of our data (employees are nested within companies, e.g. Kozlowski and Klein, 2000), we applied hierarchical linear modelling (HLM) with robust maximum likelihood estimation (MLE) to test our hypotheses and used the log-likelihood difference test to compare the nested models (Raudenbush and Bryk, 2002). The sample sizes of both the higher-level sample (70 companies) and the lowerlevel sample (11.61 employees for each company) are in line with recommendations from simulation studies (Maas and Hox, 2005), and higher than in other multilevel studies (e.g. Fong and Snape, 2015; van der Borgh, de Jong and Nijssen, 2015). Following the suggestion of Enders and Tofighi (2007), we applied group-mean centring for all exploratory variables involved in cross-level interactions (i.e. employee $\mathrm{CO}$ ), and all other predictor variables at level 1 and level 2 were grand-mean centred on their respective levels. ${ }^{3}$

\footnotetext{
${ }^{3}$ We replicated our analyses with a grand-mean centring strategy: All the results remained stable.
}

Results

The results are shown in Table 3. In Model 1.1, firm $\mathrm{CO}$ is positively related to employee $\mathrm{CO}(\gamma=0.14, p<0.001)$. In Model 1.2, a positive relationship is found between employees' $\mathrm{CO}$ and their performance $(\gamma=1.99, p<0.007)$. In Model 1.3, the cross-level interaction between employee $\mathrm{CO}$ and firm $\mathrm{CO}$ is significant $(\gamma=$ $-3.78, p<0.001$ ), yielding support for Hypothesis 1. Simple slope analysis shows that the relationship between employee $\mathrm{CO}$ and performance is positive and significant at low levels of firm $\mathrm{CO}(\gamma=3.68$, $p<0.001)$, but not at high levels of firm $\mathrm{CO}(\gamma=$ $-0.03, p=0.96$ ) (see Figure 3).

\section{Robustness tests and supplementary analysis}

We replicated our analyses with a structural equation model to rule out the possibility of measurement error biasing our results. As a supplementary analysis, we further tested for the conditional indirect effect of firm $\mathrm{CO}$ on employee performance. We used a parsimonious model and a robust MLE. The main effects model showed good fit $\left(\chi^{2}(75)=229.59, \mathrm{CFI}=0.96, \mathrm{RMSEA}=0.05\right) . \mathrm{In}$ line with suggestions from previous research (Boles et al., 2001; Cross et al., 2007), employee CO fully mediates the effect of firm $\mathrm{CO}$ on employee performance $(\gamma=0.52, p<0.09,95 \% \mathrm{CI}=0.02$; 1.00). ${ }^{4}$ Adding the interaction between firm $\mathrm{CO}$ and employee $\mathrm{CO}$ significantly improves the model fit $(-2 \mathrm{LL}$ change $=3.37, p<0.07)$ and its effect on employee performance is significant $(\gamma=-5.08$, $p<0.07$ ). The postulated moderation effect further qualifies the indirect effect of firm $\mathrm{CO}$ on employee performance: this indirect effect is positive and significant only if firm CO is low $(\gamma=0.80, p<$ $0.05,95 \% \mathrm{CI}=0.04 ; 1.57)$, but not when firm $\mathrm{CO}$ is high $(\gamma=0.24, p=0.31,95 \% \mathrm{CI}=-0.15 ; 0.63)$.

\section{Discussion}

Study 1 identifies a substitution effect whereby firm CO buffers the relationship between employees' $\mathrm{CO}$ and their performance. Specifically, we find that employee $\mathrm{CO}$ is not related to employee performance when firm $\mathrm{CO}$ is high. Moreover, post hoc analyses on the indirect effect indicate that

\footnotetext{
${ }^{4}$ All confidence intervals (CIs) for mediation effects correspond to directional one-tailed hypothesis tests.
} 


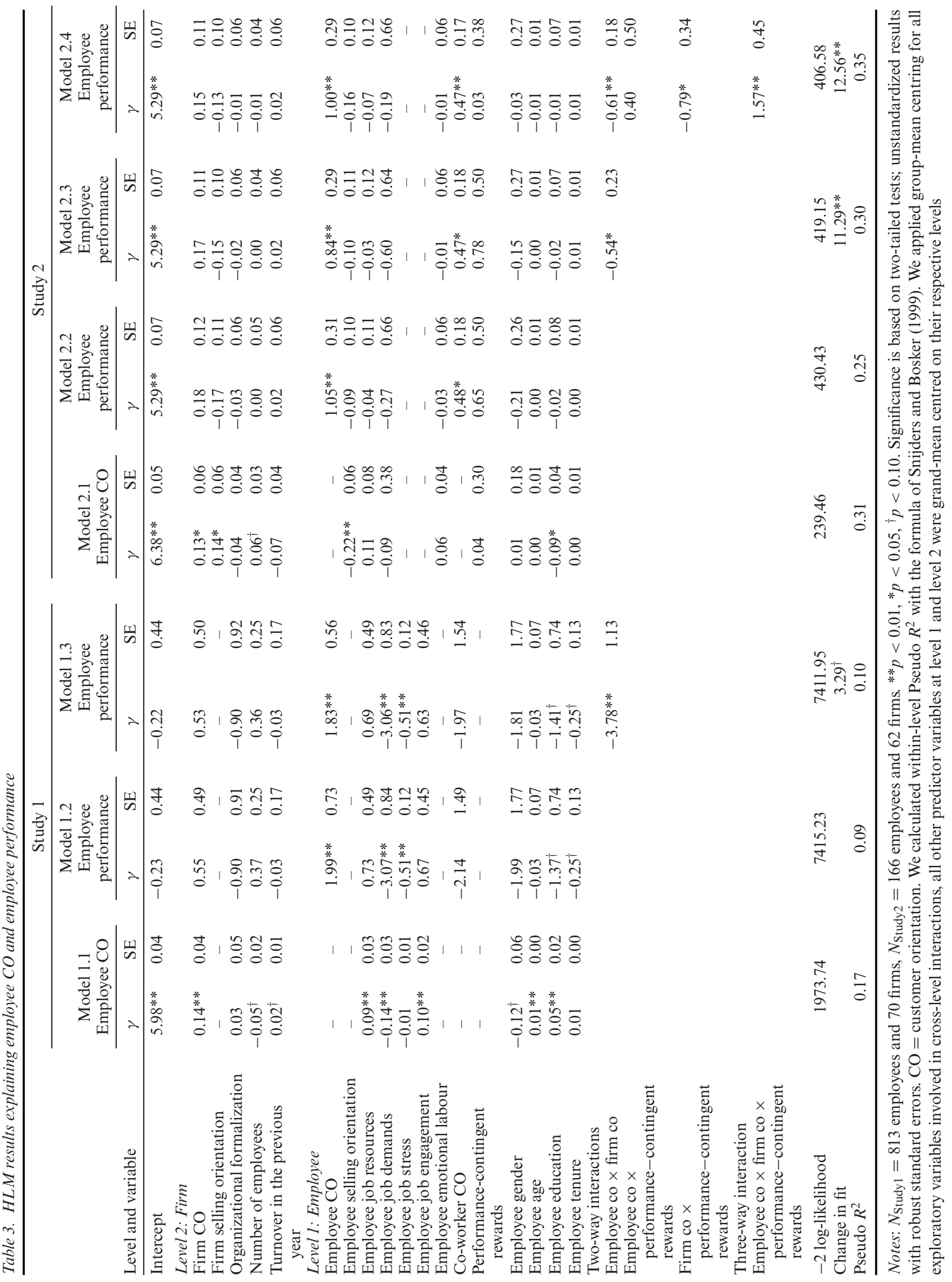


Employee Customer Orientation $\times$ Firm Customer Orientation on Employee Performance

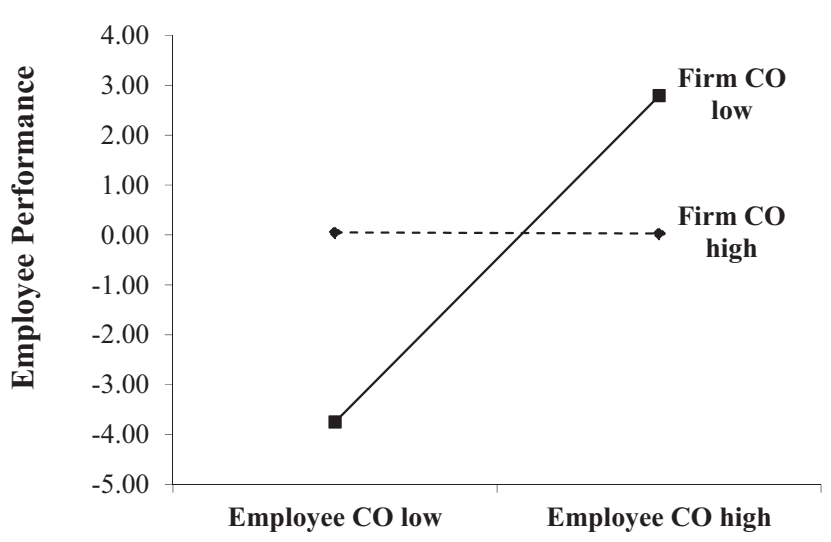

Figure 3. The interplay between employee and firm customer orientation in Study 1

Notes: $\mathrm{CO}=$ customer orientation. The dotted line represents a non-significant effect in Figure 3

firm $\mathrm{CO}$ does not indirectly contribute to employee performance through employee $\mathrm{CO}$ when firm $\mathrm{CO}$ is high. Given these findings, the question that arises is whether managers are able to resolve this substitution effect and attain the benefits of firm $\mathrm{CO}$ without generating undesired consequences for employees, namely the perception of a weak link between $\mathrm{CO}$ and individual performance. We explicitly address this question in Study 2.

\section{Study 2}

\section{Data collection and measures}

In our second study, we contacted 1924 sales employees using a database provided by the Swiss Professional Marketing Association. These salespeople work for various B2B companies with different levels of firm $\mathrm{CO}$ and with various compensation schemes, ranging from $100 \%$ fixed compensation to $100 \%$ variable compensation. We chose a B2B context because employee CO is of the greatest importance for a B2B firm's marketing strategy (e.g. Gummesson, 2004). After one follow-up, we received 382 fully completed questionnaires $(20 \%$ response rate). We did not identify systematic differences in demographics and constructs means between early and late respondents. To reduce the risk of common method bias, we only retained responses from 62 firms for which more than one employee replied in our main analyses. In taking these steps, we followed the recommendation of Podsakoff et al. (2003) to differentiate the measurement sources of the variables. As a consequence, our main analyses are based on a sample of 166 employees from 62 firms. We also replicated our analyses with the combined sample of all respondents $(n=382)$ as a robustness test.

We pre-tested all measurement scales with 24 sales managers at a professional development workshop. Appendix S2 provides an overview of all measurement items and reliability measures; Table 2 displays means, standard deviations and average variance extracted for the main sample. ${ }^{5}$ All scales had satisfactory Cronbach's alpha values. We used Thomas, Soutar and Ryan's (2001) scale to assess the $\mathrm{CO}$ of employees with direct customer contact. We measured firm $\mathrm{CO}$ with the scale used by Deshpandé, Farley and Webster (1993). The ICCs provided statistical support for aggregation at the firm level ( $\mathrm{ICC}[1]=0.62$; ICC[2] $=0.81)$. We assessed employee performance with a scale suitable for sales employees, adapted from Homburg, Müller and Klarmann (2011). All employees provided information regarding their performance-contingent rewards, operationalized as a continuous variable ranging from $100 \%$ for straight commission (salary has no role in the compensation plan) to $0 \%$ (salary has an exclusive role in the compensation plan)

\footnotetext{
${ }^{5}$ Further information about the validation sample is available upon request from the authors.
} 
(John and Weitz, 1989). We controlled for the firm's selling orientation (new measure; ICC [1] = 0.64 ; $\mathrm{ICC}[2]=0.82$ ), organizational formalization (based on Jansen, Van Den Bosch and Volberda, 2006), employee job resources (based on Plouffe et al., 2016), employee job demands (based on Marshall, Moncrief and Lassk, 1999; Moncrief and Marshall, 2005), employee emotional labour (based on Hennig-Thurau et al., 2006), co-worker CO (Menguc et al., 2016), number of employees, turnover in the previous year, and employees' selling orientation (Thomas, Soutar and Ryan, 2001), gender, age, education and tenure.

\section{Measurement model and common method bias}

The CFA indicated a good fit of the measurement model with the data $\left(\chi^{2}(194)=350.98 ; C F I=\right.$ 0.89 ; RMSEA $=0.07)$. We used the same methods as in Study 1 to reduce the potential for common method bias. In addition - and because we obtained several multi-item constructs from the same source in Study 2 - we estimated a further CFA model that included a latent method factor with paths to each item (Podsakoff et al., 2003). All substantive factor loadings remained significant, and the method factor accounted for only $5.32 \%$ of variance.

\section{Data analysis strategy}

Because employees are nested within different companies, the data structure suggests the use of multi-level modelling. While the higher-level sample size (62 companies) is well in line with common standards for multilevel models, the lower-level sample size is quite small (2.68 employees for each company). However, simulation studies justify the use of multi-level modelling despite the small lower-level sample size. For example, Maas and Hox (2005, p. 86) argued that 'only a small sample size at level two (meaning a sample of 50 or less) leads to biased estimates' and McNeish (2014, p. 558) concluded that 'both methods [multi-level modelling and generalized estimating equations] are reasonable for accounting for the clustered data structure even with sparse data containing very few observations per cluster'. Thus, we applied HLM with robust MLE and loglikelihood difference tests, group-mean centring for all exploratory variables involved in cross-level interactions (i.e. employee $\mathrm{CO}$ and performance rewards), and grand-mean centring for all other predictors. $^{6}$

\section{Results}

We obtained similar results with respect to Hypothesis 1 as in Study 1, even after controlling for the effects of firm and employee selling orientation. The interaction of employee $\mathrm{CO}$ with firm $\mathrm{CO}(\gamma=-0.54, p<0.03)$ in Model 2.3 is significant and in line with our predictions. In Model 2.4, we found a positive three-way interaction between employee $\mathrm{CO}$, firm $\mathrm{CO}$ and performance-contingent rewards $(\gamma=1.57, p<$ 0.001), supporting Hypothesis 2.

In Figure 4, we probe this three-way interaction by plotting the simple slope of employee $\mathrm{CO}$ at one standard deviation above and below the mean of firm $\mathrm{CO}$ and the mean of performance-contingent rewards. In the case of low performancecontingent rewards (panel $\mathrm{A}$ ), there is a positive effect of employee $\mathrm{CO}$ on employee performance when firm CO is low $(\gamma=1.90, p<0.001)$ and a non-significant negative effect when firm $\mathrm{CO}$ is high $(\gamma=-0.10, p=0.83 ; p<0.001$ for the slope difference test). In contrast, we find no significant difference in the positive relationship between employee $\mathrm{CO}$ and their performance between high $(\gamma=0.91, p<0.02)$ and low $(\gamma=1.30, p<0.001)$ firm $\mathrm{CO}$ when performance-contingent rewards are high (panel $\mathrm{B} ; p=0.35$ for the slope difference test). In summary, consistent with our hypothesis, the substitution effect between firm $\mathrm{CO}$ and employee $\mathrm{CO}$ on performance is not detected under a high level of performance-contingent rewards.

\section{Robustness tests and supplementary analysis}

First, we re-estimated our model using the combined sample of all respondents, including the 216 additional employees from 216 different firms. We used simple regression analysis and included the same controls as in the main analysis. The results confirm the findings from the main analyses (see Appendix S3). We found a negative interaction of employee $\mathrm{CO}$ with firm $\mathrm{CO}$ on employee performance $(b=-0.12, p<0.007)$ and

\footnotetext{
${ }^{6} \mathrm{We}$ replicated our analyses with simple regression, generalized estimating equations and a grand-mean centring strategy: all results remained stable.
} 


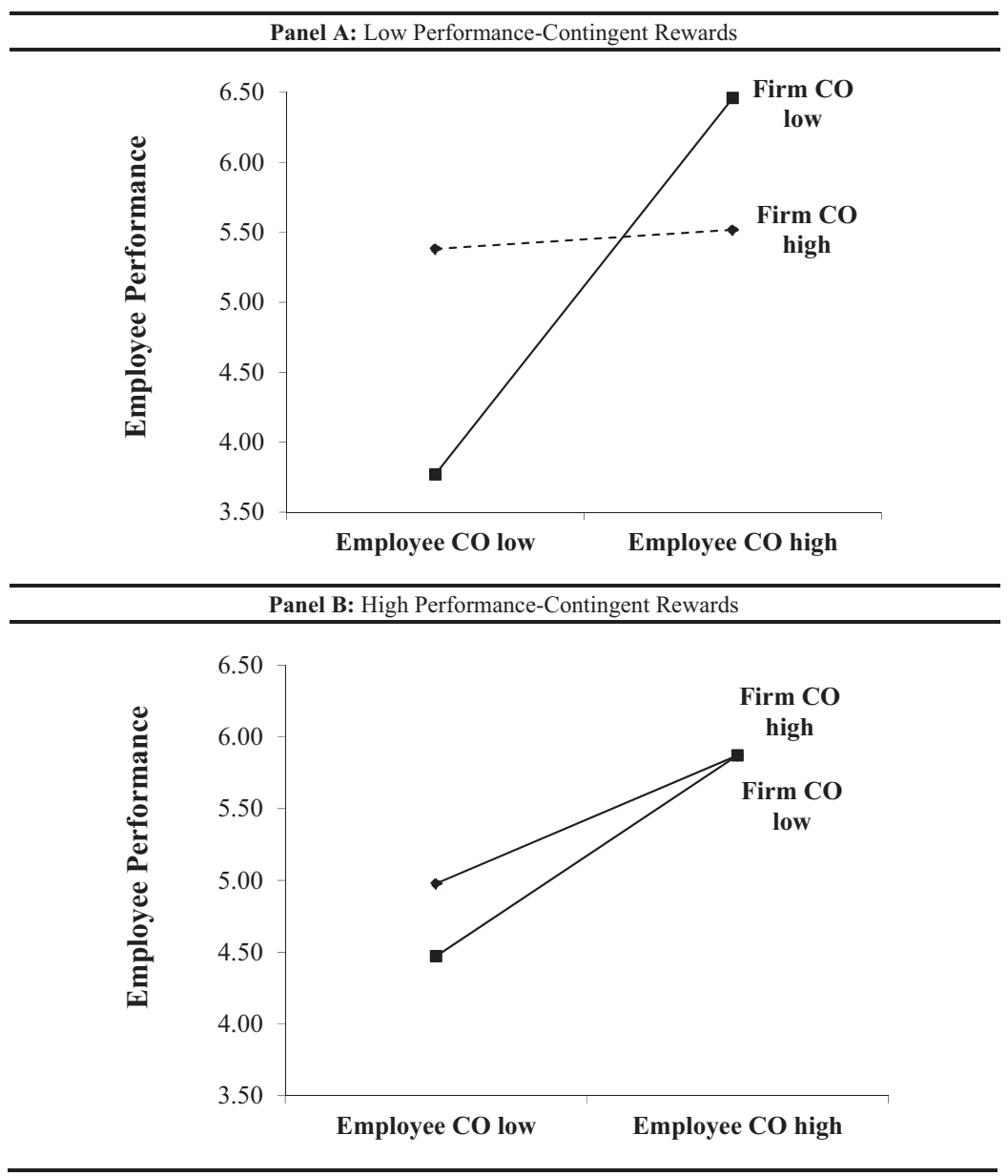

Figure 4. The contingency role of performance-related rewards in Study 2

Notes: $\mathrm{CO}=$ customer orientation. The dotted line represents a non-significant effect in Figure 4 panel $\mathrm{A}$

a positive three-way interaction between employee $\mathrm{CO}$, firm $\mathrm{CO}$ and performance-contingent rewards on employee performance $(b=1.48, p<0.001)$. Second, we replicated our analyses with an adjusted measure of employee performance relative to colleagues from the same firm (i.e. employee performance $=$ individual performance - mean individual performance within the firm) and found the same effects as in the main analysis (all hypotheses supported at $p<0.01$ ). Third, we tested whether firm $\mathrm{CO}$ affects the performancecontingent rewards of employees and found no significant effect $(b=-0.04, p=0.12)$; thus, performance-contingent rewards appear to be an independent compensation device that firms use irrespective of their $\mathrm{CO}$ level. We further replicated our analyses using a parsimonious structural equation model. The main effects model showed good fit $\left(\chi^{2}(159)=211.12, \mathrm{CFI}=0.95\right.$, RMSEA $=$ $0.05)$ and employee $\mathrm{CO}$ fully mediates the effect of firm CO on employee performance $(\gamma=0.10, p<$ $0.02,95 \% \mathrm{CI}=0.02 ; 0.19)$. Adding the interactions significantly improved model fit $(-2 \mathrm{LL}$ change $=$ 22.86, $p<0.001)$ : The interaction between employee $\mathrm{CO}$ and firm $\mathrm{CO}$ is negatively related to employee performance $(\gamma=-1.42, p<0.01)$, and the three-way interaction between employee $\mathrm{CO}$, firm $\mathrm{CO}$, and performance-contingent rewards is positively related to employee performance $(\gamma=3.03$, $p<0.03$ ). When performance-contingent rewards are low, the indirect effect of firm $\mathrm{CO}$ on employee performance is positive and significant only if firm $\mathrm{CO}$ is low $(\gamma=0.19, p<0.02,95 \% \mathrm{CI}=0.04$; $0.34)$, but not when firm $\mathrm{CO}$ is high $(\gamma=-0.05$, $p=0.48,95 \% \mathrm{CI}=-0.16 ; 0.07$ ). A Wald Test of parameter equality confirms this observation 
$\left(\Delta \chi^{2}=2.94, d f=1, p<0.05\right)$. In contrast, we found no significant difference in the indirect positive relationship between firm $\mathrm{CO}$ and employee performance between high firm $\mathrm{CO}(\gamma=0.13, p$ $<0.07,95 \% \mathrm{CI}=-0.01 ; 0.26)$ and low firm $\mathrm{CO}$ $(\gamma=0.14, p<0.02,95 \% \mathrm{CI}=0.04 ; 0.24)$ when performance-contingent rewards are high (Wald Test of parameter equality: $\Delta \chi^{2}=0.03, d f=1$, $p=0.86)$.

\section{Discussion}

Study 2 provides additional evidence that there is a substitution effect between firm $\mathrm{CO}$ and employee $\mathrm{CO}$ with respect to employee performance, and that the level of firm $\mathrm{CO}$ further affects the indirect effect on employee performance. More importantly, this study also identifies how managers can mitigate this substitutional effect by using performance-contingent rewards. Notably, we replicated our findings from the main analysis with a validation sample.

\section{General discussion}

In this paper, we identify and explain a potential tension that needs to be managed between a firm's emphasis on $\mathrm{CO}$ and employees' perception of the value of such behaviour. This is the first study to include both cross-level direct effects from firm $\mathrm{CO}$ to employee $\mathrm{CO}$ and cross-level interaction effects between firm $\mathrm{CO}$ and employee $\mathrm{CO}$ on employee performance. The simultaneous analysis of these two types of cross-level effects is important, as it brings to the surface a substitution effect. Based on SDT, and using the distinction between autonomous and controlled motivation, we propose that the link between employee $\mathrm{CO}$ and employee performance will be stronger in firms with lower levels of CO. Furthermore, we examined a boundary condition for this hypothesis and posited that when performance-contingent rewards are introduced, the substitution effect described above is weakened.

Both Study 1 and Study 2 indicate a positive cross-level effect of firm $\mathrm{CO}$ on employee $\mathrm{CO}$ and a negative cross-level moderating effect of firm $\mathrm{CO}$ on the positive relationship between employee $\mathrm{CO}$ and employee performance. In Study 2, we further found a positive three-way interaction between firm $\mathrm{CO}$, employee $\mathrm{CO}$ and performance-contingent rewards on employee performance. We were able to replicate the full set of results with a validation sample. Taken together, our findings are robust across different types of employees (back office vs. customer-contact employees), measurements of key variables (top management team vs. organizational $\mathrm{CO}$ and measurement of performance) and data sources (key informants vs. multiple informants).

\section{Theoretical implications}

We contribute to the $\mathrm{CO}$ implementation literature in three important ways. First, scholars agree that employees have two main motivations for adopting $\mathrm{CO}$ : the need to comply with the normative mandate of the firm's CO (Gebhardt, Carpenter and Sherry, 2006) and the expectation of superior individual job performance (Zablah et al., 2012). While the former can relate to both autonomous and controlled motivation, the latter is an inherently autonomous motivation, because employees rely on their own judgment in terms of whether or not to adopt a CO (Gagné and Deci, 2005). Our work reveals an interesting interplay between the emphasis a firm places on $\mathrm{CO}$ and the extent to which $\mathrm{CO}$ is an individual success factor. Consequently, we propose an extended view of the process through which managers influence the adoption of a $\mathrm{CO}$ by employees. In doing so, we integrate the autonomous and controlled motivations in the $\mathrm{CO}$ context. This is also important to qualify the indirect relationship between firm $\mathrm{CO}$ and employee performance via employee CO suggested by previous research (Boles et al., 2001; Cross et al., 2007). We formally test this indirect relationship for the first time and find that the indirect effect of firm $\mathrm{CO}$ on employee performance appears to be conditional on the level of firm CO. In summary, our model and findings suggest that neglecting to consider the two different motivations simultaneously may explain the frequent failures of $\mathrm{CO}$ initiatives within firms.

Second, with regard to the moderating role of firm $\mathrm{CO}$ in the relationship between employee $\mathrm{CO}$ and employee performance, our study contributes to the ongoing debate concerning the extent to which employees benefit from their CO. Indeed, both Franke and Park (2006) and Zablah et al. (2012) observed significant variance in the meta-analytic correlations between employee $\mathrm{CO}$ 
and performance, and the moderator analyses in their work provided mixed results. Our findings suggest that the $\mathrm{CO}$ in the broader organizational context determines the performance effects of an employee's CO. This potential moderator was not examined by previous studies and thus represents a novel finding and explanation of the heterogeneity of the employee $\mathrm{CO}$-performance relationship, given that our study takes into account additional control variables and moderators reported by previous research. In firms with low $\mathrm{CO}$, employees rely on their personal interests and enjoyment to direct their customer-oriented behaviour, and thus high employee $\mathrm{CO}$ will be less frequent but more authentic compared with firms with high CO. Thus, employees with high $\mathrm{CO}$ are more likely to outperform other employees within their firm. In contrast, in firms with high $\mathrm{CO}$, the performance effects of employees' $\mathrm{CO}$ will be diluted because $\mathrm{CO}$ initiatives instil at least some controlled motivation for employees, making employee $\mathrm{CO}$ - other things being equal - more frequent, but less likely to be internalized.

Third, our results point to a different and novel interpretation of the role and importance of performance-contingent rewards for CO. Indeed, such rewards help balance the negative effect of the normative pressure to comply with the organizational mandate, rather than working as a direct motivator to take on $\mathrm{CO}$ behaviours. This effect is due to a stronger perception of autonomy and competence as being related to $\mathrm{CO}$, which in turn drives the adoption of the behaviour in question by individual employees. Hence, an important theoretical implication of our results is that performance-contingent rewards enable a fairer redistribution of the value that employees help to create. Indeed, marketing scholars propose value creation through relational and collaborative exchanges between the firm, its representatives and its customers (Vargo and Lusch, 2008), while calling for a balanced consideration of the roles and rewards among this network of actors (Gummesson, 2008). We further find that, when performance-contingent rewards are low, the indirect effect of firm $\mathrm{CO}$ on employee performance is positive and significant only if firm $\mathrm{CO}$ is low, but not when it is high, leading to an undesired situation for firms. In contrast, we find no significant difference in the indirect positive relationship between firm $\mathrm{CO}$ and employee performance for high and low firm $\mathrm{CO}$ when performance-contingent rewards are high, further supporting the importance of performance-contingent rewards in aligning the benefits of individual and firm $\mathrm{CO}$.

\section{Managerial implications}

Our findings have direct implications for the implementation of customer-oriented initiatives within firms. Specifically, we shed light on how organizational leaders can influence the $\mathrm{CO}$ process by acting jointly on the top-down diffusion of $\mathrm{CO}$ and complementary aspects related to the work environment and performance-related pay. A first suggestion would be to include specific references to the benefits of $\mathrm{CO}$ for individual performance in various strategic initiatives (i.e. training, work procedures, internal communications) to emphasize the importance of individuals adopting CO. In companies that strongly encourage their employees to be customer-oriented, this may counterbalance the tendency towards low internalization of the behaviour. A second recommendation is to monitor and measure the perceived effectiveness of $\mathrm{CO}$ as part of the strategy implementation process, to detect the potential tension highlighted by our study. For example, using performance appraisals or staff surveys, line managers can gauge the extent to which their employees perceive $\mathrm{CO}$ as a key performance factor. Finally, we advise managers to implement appropriate performance-contingent rewards in conjunction with organizational initiatives that will promote or re-launch the adoption of customer-oriented behaviours among employees, with specific reference to the sales force. Also, our findings suggest that, rather than 'pushing' employees to become more customer-oriented, performance-contingent rewards should 'pull' employees in that direction by helping them to associate $\mathrm{CO}$ with individual performance. Thus, a further recommendation pertains to the communication of performance-related rewards. For example, rewards could be directly associated with relevant customer metrics, which in turn may be portrayed as naturally linked to the adoption of customer-oriented behaviour by individual employees. The ultimate aim here is to manage the organizational culture, environment and rewards to maximize the internalization of $\mathrm{CO}$ by individual employees. 


\section{Limitations}

The empirical results across the two studies should be interpreted bearing their limitations in mind. First, we were not able to measure explicitly the proposed mechanism that transmits the moderating effect of firm $\mathrm{CO}$ on the relationship between employee $\mathrm{CO}$ and employee performance (controlled and autonomous motivation). Although the proposed mechanism is in line with SDT and the CO literature, future research should validate the proposed process by measuring the different types of motivation. Second, the cross-sectional nature of the data does not allow us to infer causality. Further research using longitudinal data or an experimental design could address this issue. Third, because no objective measures of performance were available, we relied on employees' self-reported performance. Although empirical evidence shows that subjective measures may often 'do a better job of tapping the content domain of the performance construct' (Rich et al., 1999, p. 52) than objective measures do, future studies may seek to replicate our results with objective measures of performance. Fourth, the comparability of the studies is somewhat limited: the back-office employees in Study 1 received no substantial performance-linked incentives, Study 2 used different measures from those in Study 1, and we were only able to test for the moderating role of performance-contingent rewards with a sample of customer-contact employees. Examining whether this relationship holds for back-office employees could be worthwhile, because these employees may be subject to different compensation arrangements. Fifth, while we controlled for organizational formalization, we were not able to include 'service scripts' among our controls, because none of the participating firms use service scripts for their back-office employees and sales employees. Thus, future research should validate our model with frontline service employees and explicitly consider the role of service scripts. Finally, the substitution effects of firm $\mathrm{CO}$ may further depend on how organizations communicate $\mathrm{CO}$ to their employees and other factors, such as the ability of customers to detect surface acting, may affect the relationships proposed and tested in our model. ${ }^{7}$ Thus, investigating

\footnotetext{
${ }^{7}$ We thank an anonymous reviewer for pointing these limitations and future research directions out to us.
}

whether firms may use certain communication tactics to anticipate the substitution effect and considering how customer characteristics may affect the interplay between employee and firm $\mathrm{CO}$ are promising research directions.

\section{Future research directions}

In addition to the limitations mentioned above, our study points to interesting directions for future research. While we focus on $\mathrm{CO}$ as a prominent strategic orientation, future investigations could explore the cross-level effects examined by taking into account different dimensions of organizational culture and strategic orientation that span firms and individuals in terms of behaviours and performance implications (e.g. entrepreneurship or learning orientation). Second, our research context was homogeneous in terms of cultural traits (Hofstede, 1985). Given Hohenberg and Homburg's (2016) findings that various financial and non-financial steering instruments are differentially effective in motivating employees across cultures, future studies could replicate our analyses in countries with varying levels of individualism, power distance or uncertainty avoidance to produce interesting cross-cultural comparisons. Finally, while we reveal the importance of performance-contingent rewards, future research could examine the ability of additional elements of the work environment and job characteristics to promote autonomous motivation.

\section{References}

Allen, J. A., S. D. Pugh, A. A. Grandey and M. Groth (2010). 'Following display rules in good or bad faith? Customer orientation as a moderator of the display rule-emotional labor relationship', Human Performance, 23, pp. 101-115.

Amabile, T. M. (1993). 'Motivational synergy: toward new conceptualizations of intrinsic and extrinsic motivation in the workplace', Human Resource Management Review, 3, pp. 185201.

Amabile, T. M., K. G. Hill, B. A. Hennessey and E. M. Tighe (1994). 'The work preference inventory: assessing intrinsic and extrinsic motivational orientations', Journal of Personality and Social Psychology, 66, pp. 950-967.

Boles, J. S., B. J. Babin, T. G. Brashear and C. Brooks (2001). 'An examination of the relationships between retail work environments, salesperson selling orientation-customer orientation and job performance', Journal of Marketing Theory and Practice, 9, pp. 1-13.

Brach, S., G. Walsh, T. Hennig-Thurau and M. Groth (2015). 'A dyadic model of customer orientation: mediation and moderation effects', British Journal of Management, 26, pp. 292-309. 
Cerasoli, C. P., J. M. Nicklin and M. T. Ford (2014). 'Intrinsic motivation and extrinsic incentives jointly predict performance: a 40-year meta-analysis', Psychological Bulletin, 140, pp. $980-1008$.

CMO Council (2008). 'Technology marketers challenged to reorganize around customers'. Available at http://www. cmocouncil.org/press-detail.php?id=103 [accessed 2 August 2015].

Cross, M. E., T. G. Brashear, E. E. Rigdon and D. N. Bellenger (2007). 'Customer orientation and salesperson performance', European Journal of Marketing, 41, pp. 821-835.

Deci, E. L., R. Koestner and R. M. Ryan, (1999). 'A metaanalytic review of experiments examining the effects of extrinsic rewards on intrinsic motivation', Psychological Bulletin, 125, pp. 627-668.

Deshpandé, R., J. U. Farley and F. E. Webster Jr (1993). 'Corporate culture, customer orientation, and innovativeness in Japanese firms: a quadrad analysis', Journal of Marketing, 57, pp. 23-37.

Donavan, T. D., T. J. Brown and J. C. Mowen (2004). 'Internal benefits of service-worker customer orientation: job satisfaction, commitment, and organizational citizenship behaviours', Journal of Marketing, 68, pp. 128-146.

Dwyer, D. J. and D. C. Ganster (1991). 'The effects of job demands and control on employee attendance and satisfaction', Journal of Organizational Behavior, 12, pp. 595608.

Enders, C. K. and D. Tofighi (2007), 'Centering predictor variables in cross-sectional multilevel models: a new look at an old issue', Psychological Methods, 12, pp. 121-138.

Fong, C. T. and L. Z. Tiedens (2002). 'Dueling experiences and dual ambivalences: emotional and motivational ambivalence of women in high status positions', Motivation and Emotion, 26, pp. 105-121.

Fong, K. H. and E. Snape (2015). 'Empowering leadership, psychological empowerment and employee outcomes: testing a multi-level mediating model', British Journal of Management, 26, pp. 126-138.

Franke, G. R. and J. E. Park (2006). 'Salesperson adaptive selling behaviour and customer orientation: a meta-analysis', Journal of Marketing Research, 43, pp. 693-702.

Gagné, M. and E. L. Deci (2005). 'Self-determination theory and work motivation', Journal of Organizational Behavior, 26, pp. 331-362.

Gebhardt, G. F., G. S. Carpenter and J. F. Sherry Jr (2006). 'Creating a market orientation: a longitudinal, multifirm, grounded analysis of cultural transformation', Journal of Marketing, 70, pp. 37-55.

Gerhart, B. and M. Fang (2015). 'Pay, intrinsic motivation, extrinsic motivation, performance, and creativity in the workplace: revisiting long-held beliefs', Annual Review of Organizational Psychology and Organizational Behavior, 2. pp. $489-521$.

Grant, A. M. (2008). 'Does intrinsic motivation fuel the prosocial fire? Motivational synergy in predicting persistence, performance, and productivity', Journal of Applied Psychology, 93, pp. 48-58.

Grant, A. M., S. Nurmohamed, S. J. Ashford and K. Dekas (2011). 'The performance implications of ambivalent initiative: the interplay of autonomous and controlled motivations', Organizational Behavior and Human Decision Processes, 116, pp. 241-251.
Guenzi, P., L. M. De Luca and G. Troilo (2011). '. 'Organizational drivers of salespeople's customer orientation and selling orientation', Journal of Personal Selling \& Sales Management, 31, pp. 269-285.

Gummesson, E. (2004). 'Return on relationships (ROR): the value of relationship marketing and CRM in business-tobusiness contexts', Journal of Business \& Industrial Marketing, 19, pp. 136-148.

Gummesson, E. (2008). 'Extending the service-dominant logic: from customer centricity to balanced centricity', Journal of the Academy of Marketing Science, 36, pp. 15-17.

Harris, L. C. and E. Ogbonna (2000). 'The responses of frontline employees to market-oriented culture change', European Journal of Marketing, 34, pp. 318-340.

Hennig-Thurau, T., M. Groth, M. Paul and D. D. Gremler (2006). 'Are all smiles created equal? How employee-customer emotional contagion and emotional labor affect service relationships', Journal of Marketing, 70, pp. 58-73.

Hofstede, G. (1985). 'The interaction between national and organizational value systems', Journal of Management Studies, 22, pp. 347-357.

Hohenberg, S. and C. Homburg (2016). 'Motivating sales reps for innovation selling in different cultures', Journal of Marketing, 80, pp. 101-120.

Homburg, C., M. Müller and M. Klarmann (2011). 'When should the customer really be king? On the optimum level of salesperson customer orientation in sales encounters', Journal of Marketing, 75, pp. 55-74.

Jansen, J. J., F. A. Van Den Bosch and H. W. Volberda (2006). 'Exploratory innovation, exploitative innovation, and performance: effects of organizational antecedents and environmental moderators', Management Science, 52, pp. 1661-1674.

John, G. and B. Weitz (1989). 'Salesforce compensation: an empirical investigation of factors related to use of salary versus incentive compensation', Journal of Marketing Research, 26, pp. 1-14.

Kennedy, K. N., F. G. Lassk and J. R. Goolsby (2002). 'Customer mind-set of employees throughout the organization', Journal of the Academy of Marketing Science, 30, pp. 159-171.

Kozlowski, S. and K. J. Klein (2000). 'A multilevel approach to theory and research in organizations: contextual, temporal, and emergent processes'. In K. J. Klein and S. Kozlowski (eds), Multilevel Theory, Research, and Methods in Organizations: Foundations, Extensions, and New Directions, pp. 3-90. San Francisco, CA: Jossey-Bass.

Liao, H. and A. Chuang (2004). 'A multilevel investigation of factors influencing employee service performance and customer outcomes', Academy of Management Journal, 47, pp. 41-58.

Liao, H. and M. Subramony (2008). 'Employee customer orientation in manufacturing organizations: joint influences of customer proximity and the senior leadership team', Journal of Applied Psychology, 93, pp. 317-328.

Lichtenthal, J. D. and D. T. Wilson (1992). 'Becoming market oriented', Journal of Business Research, 24, pp. 191-207.

Lin, C. H. V., K. Sanders, J. M. J. Sun, H. Shipton and E. A. Mooi (2016). 'From customer-oriented strategy to organizational financial performance: the role of human resource management and customer-linking capability', British Journal of Management, 27, pp. 21-37.

Maas, C. J. and J. J. Hox (2005). 'Sufficient sample sizes for multilevel modeling', Methodology, 1, pp. 86-92. 
MacKenzie, S. B., P. M. Podsakoff and G. A. Rich (2001). 'Transformational and transactional leadership and salesperson performance', Journal of the Academy of Marketing Science, 29, pp. $115-134$.

Marshall, G. W., W. C. Moncrief, and F. G. Lassk (1999). 'The current state of sales force activities', Industrial Marketing Management, 28, pp. 87-98.

McNeish, D. M. (2014). 'Modeling sparsely clustered data: design-based, model-based, and single-level methods', Psychological Methods, 19, pp. 552-563.

Menguc, B., S. Auh, C. S. Katsikeas and Y. S. Jung (2016). 'When does (mis)fit in customer orientation matter for frontline employees' job satisfaction and performance?', Journal of Marketing, 80, pp. 65-83.

Moncrief, W. C. and G. W. Marshall (2005). 'The evolution of the seven steps of selling', Industrial Marketing Management, 34, pp. 13-22.

Narver, J. C. and S. F. Slater (1990). 'The effect of a market orientation on business profitability', Journal of Marketing, 54, pp. 20-35.

Plouffe, C. R., W. Bolander, J. A. Cote and B. Hochstein (2016). 'Does the customer matter most? Exploring strategic frontline employees' influence of customers, the internal business team, and external business partners', Journal of Marketing, 80, pp. 106-123.

Podsakoff, P. M., S. B. MacKenzie, J.-Y. Lee and N. P. Podsakoff (2003). 'Common method biases in behavioural research: a critical review of the literature and recommended remedies', Journal of Applied Psychology, 88, pp. 879-903.

Procter, S., L. McArdle, J. Hassard and M. Rowlinson (1993). 'Performance related pay in practice: a critical perspective', British Journal of Management, 4, pp. 153-160.

Raudenbush, S. W. and A. S. Bryk (2002). Hierarchical Linear Models: Applications and Data Analysis Methods. London: Sage Publications.

Rich, G. A., W. H. Bommer, S. B. MacKenzie, P. Podsakoff and J. L. Johnson (1999). 'Apples and apples or apples and oranges? A meta-analysis of objective and subjective measures of salesperson performance', Journal of Personal Selling \& Sales Management, 29, pp. 41-52.

Rich, B. L., J. A. Lepine, and E. R. Crawford (2010). 'Job engagement: antecedents and effects on job performance', Academy of Management Journal, 53, pp. 617-635.
Ryan, R. M. and E. L. Deci (2000). 'Self-determination theory and the facilitation of intrinsic motivation, social development, and well-being', American Psychologist, 55, pp. 68-78.

Ryan, R. M., V. Mims and R. Koestner (1983). 'Relation of reward contingency and interpersonal context to intrinsic motivation: a review and test using cognitive evaluation theory,' Journal of Personality and Social Psychology, 45, pp. 736750.

Schmitz, C. and S. Ganesan (2014). 'Managing customer and organizational complexity in sales organizations', Journal of Marketing, 78, pp. 59-77.

Snijders, T. A. B. and R. J. Bosker (1999). An Introduction to Basic and Advanced Multilevel Modelling. London: Sage.

Stock, R. M. and W. D. Hoyer (2005). 'An attitude-behaviour model of salespeople's customer orientation', Journal of the Academy of Marketing Science, 33, pp. 536-552.

Thomas, R. W., G. N. Soutar and M. M. Ryan (2001). 'The selling orientation-customer orientation (S.O.C.O.) scale: a proposed short form', Journal of Personal Selling \& Sales Management, 21, pp. 63-70.

van der Borgh, M., A. de Jong and E. J. Nijssen (2015). 'Alternative mechanisms guiding salespersons' ambidextrous product selling', British Journal of Management, https://doi.org/ 10.1111/1467-8551.12148

Vargo, S. L. and R. F. Lusch (2008). 'Service-dominant logic: continuing the evolution', Journal of the Academy of Marketing Science, 36, pp. 1-10.

Wieseke, J., M. Ahearne, S. K. Lam and R. van Dick (2009). 'The role of leaders in internal marketing: a multilevel examination through the lens of social identity theory', Journal of Marketing, 73, pp. 123-145.

Williams, M. R. and J. S. Attaway (1996). 'Exploring salespersons' customer orientation as a mediator of organizational culture's influence on buyer-seller relationships', Journal of Personal Selling \& Sales Management, 16, pp. 33-52.

Yoo, J. J. and T. J. Arnold (2016). 'Frontline employee customeroriented attitude in the presence of job demands and resources the influence upon deep and surface acting', Journal of Service Research, 19, pp. 102-117.

Zablah, A. R., G. R. Franke, T. J. Brown and D. E. Bartholomew (2012). 'How and when does customer orientation influence frontline employee job outcomes? A meta-analytic evaluation', Journal of Marketing, 76, pp. 21-40.

Dennis Herhausen (PhD, University of St. Gallen) is Assistant Professor of Marketing at the Institute of Marketing, University of St. Gallen. His research focuses on marketing strategy implementation, customer relationships, digital marketing, and channel management. His work has been published in the Journal of Retailing, Journal of Business Research, Journal of Managerial Psychology, Management Decision and the Academy of Management Best Paper Proceedings, among others.

Luigi M. De Luca (PhD, Bocconi University) is Professor of Marketing and Innovation at Cardiff Business School, Cardiff University. His research revolves around the themes of Innovation, Marketing Strategy, Knowledge and Organizational Learning, Big Data and Decision-Making. His work has been published in the Journal of Marketing, Journal of Product Innovation Management, Research Policy, Industrial Marketing Management and Journal of Personal Selling and Sales Management, among others. 
Michael Weibel (PhD, University of St. Gallen) is a post-doctoral research fellow at the Institute of Marketing, University of St. Gallen. He is also a management trainer as well as founder and CEO of the Centre for Industrial Marketing St. Gallen AG, a consulting firm which covers all strategically relevant topics contribute to the customer's success. Michael Weibel's research focuses on business-to-business marketing and sales management.

\section{Supporting Information}

Additional Supporting Information may be found in the online version of this article at the publisher's website:

Appendix S1. Measurement of constructs in Study 1 Appendix S2. Measurement of constructs in Study 2

Appendix S3. Simple regression results in the full sample of Study 2 